\title{
Efficacy of Short and Mono segment Spinal Fixations in Traumatic Incomplete Thoracolumbar Burst Fractures
}

\author{
Binod Bhattarai, ${ }^{1}$ Sashi Shah ${ }^{1}$ \\ ${ }^{1}$ Department of Neurosurgery, College of Medical Sciences, Bharatpur-10, Chitwan, Nepal.
}

\begin{abstract}
Background: Controversies still mount over the long segment, short segment and mono segment screw fixation for traumatic thoracolumbar spine burst fractures. This article aims to provide our initial experience of the effectiveness of these management modalities with additive focus on their potential benefits upon preventing the loss of correction over time. Methods: We included all operated cases of thoracolumbar fractures presenting with the ASIA grade of above ' $C$ ' between December 2014to December 2017 in a retrospective manner in terms of operative time, estimated intra-operative blood loss, any post-operative surgical wound complications, implant cost, average time lapse for the patients to return to physiotherapy and the follow up radiological imaging at 6 months. Results: Long segment fixation is comparatively more time consuming with considerable blood loss and high incidence of postoperative wound complications. We observed that both short as well as mono segment crew fixations had similar incidences with regards to the common complications pertaining to the spinal implant placement procedures. Conclusions: Both short and mono-segment fixation procedures resulted in comparable short and long term results. Though long segment fixation is comparatively more stable, it is, however, expensive with a higher incidence of other postoperative complications.
\end{abstract}

Keywords: long segment fixation, mono segment fixation; short segment fixation; thoracolumbar burst fractures.

\section{INTRODUCTION}

Thoracolumbar spine fractures account for the most common location implicated during spinal injuries. Transitional zone of the region predisposes for vertebral body collapse and kyphotic encroachment upon the spinal canal thereby harbingering for neurological deficits. ${ }^{2}$ Despite its high incidence, there has not been a specific consensus with regards to the ideal approaches during its surgical management. The anterior approach offers direct neural decompression with provision for inserting high load-bearing implants thereby minimizing the risk of implant failures. ${ }^{3}$ This modality in a study provided high fusion rate and improvement in neurological status by at least one Frankel grading in almost $95 \%$ of cases. ${ }^{4}$ It also demonstrated more effective correction for kyphotic deformity. ${ }^{5}$

The posterior approach is a comparatively more familiar surgical corridor to most operating surgeons and provides indirect decompression through postural reduction and longitudinal distracting force from the intact longitudinal ligament. ${ }^{8}$ Herein we try to study the outcome differences between short segment fixations (excluding the involved segment) with monosegment fixation (inclusion of the involved segment) in traumatic thoracolumbar burst fractures.

\section{METHODS}

This is a cross-sectional study conducted in College of Medical Sciences-teaching hospital where 32 operated cases of thoraco-lumbar fractures between December 2014 to December 2017 was included in a retrospective manner in terms of operative time, estimated intra-operative blood loss, any postoperative surgical wound complications, implant cost, average time lapse for the patients to return to physiotherapy and the follow up radiological imaging at 12 months. Ethical approval was taken from Institutional Review Committee of

\section{Inclusion criteria}

- All thoracolumbar traumatic fractures presenting with ASIA grade equal or above Type ' $\mathrm{C}$ '.

- Age $>18$ years.

- Sagital index $>15$ degree.

- Loss of anterior body height $>30 \%$.

- Refractory pain at fracture site.

- Intact Pedicles of affected vertebra for monosegment fixation

\section{Exclusion criteria}

- Presenting neurological status below ASIA Type 'C'.

- Damage to pedicles (monosegment fixation).

- Significant polytrauma with hemodynamic instability.

Correspondence: Dr. Binod Bhattarai, Department of Neurosurgery, College of Medical Sciences and Teaching Hospital, Bharatpur-10, Chitwan, Nepal. Email: neurobinod@gmail.com. Phone: +977-9855050147. Article received: 2019-03-05. Article accepted: 2019-06-11. 
- Concomitant other spinal level injuries.

- Severe osteoporosis.

- Failure to provide consent for participation in the study.

- Lost to follow up within the study period.

The patients were managed with either a short segment (SSF) or a monosegment (MSF) posterior pedicle screw fixation. The location and projection of pedicle screws were confirmed by the use of intra-operative $\mathrm{C}$-arm images and post-operative $\mathrm{CT}$ images. To reduce the confounding biases, the same operating team performed the surgical procedures in all the cases. Though efforts were made in utilizing Medtronic implants in all the patients, due to financial restrain, we had to resort for low cost alloy implants in few patients. Radiological evaluation was assessed by CT spine in the first post operative day followed by plain Xray at 1, 3,6 and 12 months respectively for ruling out any implant failure and sequential assessment of bony fusion. Fusion was conferred with presence of at least one inter-transverse continuous bony ridge. All the patients were instructed for early assisted mobilization under thoracolumbar brace application and structured physiotherapy following the surgery. Written consent was obtained from all the patients who were included in this study. Ethical clearance was obtained from the Institutional Review and Academic Committee of the College of Medical Sciences, Chitwan, Nepal.

\section{RESULTS}

Short segment fixation (SSF) was carried out in 16 patients whereas mono-segment fixation $(\mathrm{SSF}+\mathrm{MSF})$ was performed in another 16 patients.

\section{Intraoperative parameters}

Short segment fixation was less time consuming as a segment of fixation as well as the hardware used were comparatively less (Table 1). Blood loss was similar for SSF and SSF+IS as the surgical exposure was similar (Table 1).

\begin{tabular}{|lll|}
\hline \multicolumn{2}{|l|}{ Table 1. Operating time and blood loss in SSF and } \\
MSF techniques.
\end{tabular}

Postoperative parameters

It was easier for cases with SSF and SSF + MSF for early postoperative mobilization due to smaller surgical trauma and comparatively minimal tissue retraction during the procedure (Table 2).

\section{Hardware failure}

One hardware failure was encountered in one patient as he did not comply with the instruction of

\begin{tabular}{|c|c|c|}
\hline Type & $\begin{array}{l}\text { Wound } \\
\text { infection }\end{array}$ & $\begin{array}{l}\text { Return to ambulation } \\
\text { (days) }\end{array}$ \\
\hline SSF & 2 & $4 \pm 2$ \\
\hline $\mathrm{SSF}+\mathrm{MSF}$ & 2 & $4 \pm 2$ \\
\hline
\end{tabular}

wearing the thoracolumbar belt during mobilization. He was in drug withdrawal syndrome being managed in a rehabilitation facility wherein he was flexing and extending his spine without any external support.

\section{Post-operative kyphosis}

None of the cases showed postoperative increased kyphosis during their one year follow up visits.

\section{DISCUSSION}

Short segment fixation amounts to shorter operative time, minimal blood loss and incorporation of lesser motion segments during fixation thereby minimizing adjacent segment degeneration. This approach also facilitates quicker mobilization, minimal opiate use and improved cost savings to the patients. ${ }^{7,8}$ With the provision of small incisions and thereby minimized trauma to posterior musculo -ligament complex allowing for a more rapid rehabilitation. ${ }^{9}$ It also benefits in minimizing infection rates. ${ }^{10}$ The screw on the affected vertebrae during mono-segment fixation adds up to the constructed support thereby reducing implant failures.11 There is also no provision for added bone graft fusion following short segment pedicle screw fixation. ${ }^{12}$ This eliminates bone graft donor site morbidities as well as reduces overall operative time. $^{13,14}$

There are studies implicating spontaneous canal remodeling thereby obviating the need for canal decompression that can further hinder the spinal stability by hampering the posterior column. ${ }^{15,16}$ Others have advocated for direct decompression by tapping method to the retropulsed fragments to enhance the chances of neurological improvement. ${ }^{17}$ Some authors also advocated injecting calcium cement for restoring body height and thereby combating risk of kyphotic deformity. ${ }^{18,19}$ Wang et al., even implicated the aspects of percutaneous pedicle screw fixation only without decompression for patients with minimal deficits, within ASIA grade D or E and less than $1 / 3$ of canal encroachment achieving similar clinical results in terms compared to the conventional surgery. ${ }^{20}$ MSF may be unsuitable in cases with significant damage to inferior endplates. ${ }^{21}$ Disc degeneration is common adjacent to the fractured endplates. Though implants further accelerated this process, they had significant impact upon the clinical outcome. ${ }^{22}$ Oner et al., accounted 
such changes to the index trauma to endplates following confirmation of preserved signal intensity within discs. ${ }^{23}$ Yang et al., also concluded that consequences of disc degeneration would not be a concern in cases with intact longitudinal ligaments. Discs degenerations following implant removal also did not impact much upon clinical results owing to their intact range of motion integrity. ${ }^{24,25}$ Some studies have shown poor results with SSPF. ${ }^{26}$ The loss of integrity of the anterior column with subsequent kyphosis in conjunction to osteoporosis as well as compromised fixation points amounted to implant failure. ${ }^{27-34}$ Guven et al., concluded least correction of kyphotic deformity as well restoration of anterior vertebral height in SSPF. ${ }^{35}$

Long-segment posterior pedicle screw fixation (LSPF) governs greater stability but at the expense of sacrificing motion segments. They increase intradiscal pressure and thereby accelerate adjacent segment degeneration. ${ }^{36,37} \mathrm{~A}$ cadaveric study has shown mono-segment fixation providing more biomechanical stability as well as maintenance of kyphotic correction than traditional SSPF. ${ }^{38,39}$ The kyphotic change is subsequent to damage to the adjacent endplates at the time of fracture. ${ }^{40}$ Implant failure also depends on the material used such as Titanium to confer better strength to sustain them throughout the process of fracture healing. ${ }^{41}$ There has been reports suggesting the utilization of screw size of around $60-80 \%$ of outer pedicle cortical diameter to facilitate the pedicle expansion thereby

\section{REFERENCES}

1. Dai LY, Yao WF, Cui YM, Zhou Q. Thoracolumbar fractures in patients with multiple injuries: diagnosis and treatment-a review of 147 cases. J Trauma 2004; 56:348 55.

2. Park S-H et al. Short segment percutaneous pedicle screw fixation after direct spinal canal decompression in thoracolumbar burst fractures: An alternative option. J Clin Neurosci (2018), j.jocn.2018.04.039

3. Shono Y, McAfee PC, Cunningham BW: Experimental study of thoracolumbar burst fractures. A radiographic and biomechanical analysis of anterior and posterior instrumentation systems. Spine 1994; 19:171122.

4. Kaneda K, Taneichi H, Abumi K, Hashimoto T, Satoh S, Fujiya M. Anterior decompression and stabilization with the Kaneda device for thoracolumbar burst fractures associated with neurological deficits. J Bone Joint Surg Am 1997; 79:69-83.

5. Sasso RC, Best NM, Reilly TM, McGuire RA Jr. Anterior-only stabilization of three-column thoracolumbar injuries. J Spinal Disord Tech 2005;18(suppl): S7-S14. increasing the implant stability. ${ }^{42,43}$ Another important aspect governing better outcome of this technique is linked to integrity of the posterior element. The posterior complex provides support and prevent instrument failure and furthermore its removal has not been efficacious in improving neurological outcome. ${ }^{44-46}$ Because preservation of the posterior column leads to the reduction of stress in the injured anterior and middle columns, it may prevent early instrumentation failure. ${ }^{46}$ Current literature recommends short and monosegment fixation techniques to be limited to flexiondistraction or Chance-type vertebral injuries only.

\section{CONCLUSIONS}

Both short and monosegment fixations fared similar results comparable to the long segment fixation methods in traumatic thoracolumbar fractures. However, the results should be validated through high volume and multicentric randomized control studies.

\section{Limitation of the study}

There are certain limitations to our studies. Foremost being low inclusions of cohort groups in the study. Secondly, a long term follow up analysis is justified in terms of neurological outcome in the patients as well as the status of the fusion and stability of the involved segments.

\section{Conflict of Interest: None}

6. Wessberg $\mathrm{P}$, Wang $\mathrm{Y}$, Irstam L, Nordwall A. The effect of surgery and remodeling on spinal canal measurements after thoracolumbar burst fractures. Eur Spine J 2001; 10:55-63.

7. Andrea Perera, Anjum Qureshi \& John Edward Brecknell (2015) Mono-segment fixation of thoracolumbar burst fractures, British Journal of Neurosurgery, 29:3, 358-

361, DOI: $10.3109 / 02688697.2014 .987216$

8. Clarke A. Why are we trying to reduce length of stay? Evaluation of the costs and benefits of reducing time in hospital must start from the objectives that govern change. Qual Health Care 1996; 5:172 - 9 .

9. Lee KH, Yue WM, Yeo W, Soeharno H, Tan SB. Clinical and radiological outcomes of open versus minimally invasive transforaminal lumbar interbody fusion. Eur Spine J 2012;21: $2265-70$.

10. Leong G, Wilson J, Charlett A. Duration of operation as a risk factor for surgical site infection: comparison of English and US data. J Hosp Infect 2006; 63:255 - 62.

11. Mahar A, Kim C, Wedemeyer M, Mitsunaga L, Odell T, Johnson B, et al. Short segment fixation of lumbar burst fractures using pedicle fixation at the level of the fracture. Spine (Phila Pa 1976) 2007; 32:1503-7. 
12. Tang J, Liu Y, Cao Z, Hu Y, Lu X, Lin B. Short segment screw fixation without fusion in treatment for unstable thoracolumbar burst fracture. International Journal of Clinical and Experimental Medicine. 2014;7(12):5681-5685.

13. Wang ST, Ma HL, Liu CL, et al. Is fusion necessary for surgically treated burst fractures of the thoracolumbar and lumbar spine? A Prospective, Randomized Study. Spine 2006; 31: $2646-52$.

14. Schimmel JJ, Horsting PP, de Kleuver M, Wonders G, van Limbeek J. Risk factors for deep surgical site infections after spinal fusion. Eur Spine J 2010; 19:1711 - 9.

15. de Klerk LW, Fontijne WP, Stijnen T, Brahman $\mathrm{R}$, Tanghe HL, van Linge B. Spontaneous remodeling of the spinal canal after conservative management of thoracolumbar burst fractures. Spine (Phila Pa 1976) 1998; 23:1057-60.

16. Dai LY. Remodeling of the spinal canal after thoracolumbar burst fractures. Clin Orthop Relat Res 2001;119-23.

17. Park S-H et al. Short segment percutaneous pedicle screw fixation after direct spinal canal decompression in thoracolumbar burst fractures: An alternative option. J Clin Neurosci (2018), https://doi.org/10.1016/j.jocn.2018.04.039

18. Liao JC, Fan KF, Chen WJ. Posterior instrumentation with transpedicular calcium sulphate graft for thoracolumbar burst fracture. Int Orthop (SICOT) 2009; 33: 1669 - 75.

19. Korovessis P, Repantis T, George P. Treatment of acute thoracolumbar burst fractures with kyphoplasty and short pedicle screw fixation: transpedicular intracorporeal grafting with calcium phosphate: a prospective study. Indian J Orthop 2007; 41: $354-61$.

20. Ni WF, Huang YX, Chi YL, Xu HZ, Lin Y, Wang XY, et al. Percutaneous pedicle screw fixation for neurologic intact thoracolumbar burst fractures. J Spinal Disord Tech 2010; 23:530-7.

21. Andrea Perera, Anjum Qureshi \& John Edward Brecknell (2015) Mono-segment fixation of thoracolumbar burst fractures, British Journal of Neurosurgery, 29:3, 358361, DOI: 10.3109/02688697.2014.987216

22. Wang J, Zhou Y, Zhang ZF, et al. Radiological study on disc degeneration of thoracolumbar burst fractures treated by percutaneous pedicle screw fixation. Eur Spine J 2013; 22: 489 - 94.

23. Oner FC, van der Rijt RR, Ramos LMP, et al. Changes in the disc space after fractures of the thoracolumbar spine. J Bone Joint Surg $\mathrm{Br}$ 1998; 80B: $833-9$.

24. Yang H, Shi JH, Ebraheim M, et al. Outcome of thoracolumbar burst fractures treated with indirect reduction and fixation without fusion. Eur Spine J 2011; 20: 380 - 6 .
25. Toyone T, Ozawa T, Inada K. et al. Short segment fixation without fusion for thoracolumbar burst fractures with neurological deficit can preserve thoracolumbar motion without resulting in post-traumatic disc degeneration: a 10-year follow-up study. Spine (Phila Pa 1976) 2013;38(17):1482-1490.

26. Waqar M, Van-Popta D, Barone DG, et al. Short versus long-segment posterior fixation in the treatment of thoracolumbar junction fractures: a comparison of outcomes. $\mathrm{Br} \mathrm{J}$ Neurosurg 2016; 31:1-4.

27. Ebelke DK, Asher MA, Neff JR, Kraker DP. Survivorship analysis of VSP spine instrumentation in the treatment of thoracolumbar and lumbar burst fracture. Spine 1991;16: S428-32.

28. McCormack T, Karaikovic E, Gaines RW. The load sharing classification of spine fractures. Spine 1994; 19:1741-4.

29. McLain RF, Sparling E, Benson DR. Early failure of short-segment pedicle instrumentation for thoracolumbar fractures. J Bone Joint Surg Am 1993;75: 162-167.

30. Speth MJ, Oner FC, Kadic MA, de Klerk LW, Verbout AJ. Recurrent kyphosis after posterior stabilization of thoracolumbar fractures: 24 cases treated with a Dick internal fixator followed for 1.5-4 years. Acta Orthop Scand. 1995; 66(5):406-410.

31. Parker JW, Lane JR, Karaikovic EE, Gaines RW. Successful short-segment instrumentation and fusion for thoracolumbar spine fractures: a consecutive 4 1/2-year series. Spine (Phila $\mathrm{Pa}$ 1976). 2000; 25(9):1157-1170.

32. McLain RF, Sparling E, Benson DR. Early failure of short-segment pedicle instrumentation for thoracolumbar fractures: a preliminary report. J Bone Joint Surg Am. 1993; 75(2):162167.

33. Gurwitz GS, Dawson J, McNamara MJ, Federspiel CS, Spengler DM. Biomechanical analysis of three surgical approaches for lumbar burst fractures using short segment instrumentation. Spine. 1993; 18:977-982.

34. Alanay A, Acarolu E, Yazici M, Oznur A, Surat A. Short-segment pedicle instrumentation of thoracolumbar burst fractures: does transpedicular intracorporeal grafting prevent early failure. Spine. 2001; 26(2):213-217.

35. Guven O, Kocaoglu B, Bezer M, Aydin N, Nalbantoglu U. The use of screw at the fracture level in the treatment of thoracolumbar burst fractures. J Spinal Disord Tech. 2009; 22(6):417 $-421$.

36. Dmitriev AE, Kuklo TR, Lehman RA Jr, Rosner MK. Stabilizing potential of anterior, posterior, and circumferential fixation for multilevel cervical arthrodesis: an in vitro human cadaveric study of the operative and 
adjacent segment kinematics. Spine (Phila Pa 1976). 2007; 32(6): E188-E196.

37. Kasliwal MK, Shaffrey CI, Lenke LG, Dettori JR, Ely CG, Smith JS. Frequency, risk factors, and treatment of distal adjacent segment pathology after long thoracolumbar fusion: a systematic review. Spine (Phila Pa 1976). 2012; 37(suppl 22): S165-S179

38. Mahar A, Kim C, Wedemeyer M, Mitsunaga L, Odell T, Johnson B et al. Short-segment fixation of lumbar burst fractures using pedicle fixation at the level of the fracture. Spine. 2007; 32 (14):1503-1507.

39. Guven O, Kocaoglu B, Bezer M, Aydin N, Nalbantoglu U. The use of screw at the fracture level in the treatment of thoracolumbar burst fractures. J Spinal Disord. 2009; 22(6):417-421.

40. Aono H, et al. Surgical outcomes of temporary short-segment instrumentation without augmentation for thoracolumbar burst fractures. Injury (2016), http://dx.doi.org/10.1016/ j.injury.2016.03.003

41. Brunette DM, Tengvall P, Textor M, Thomsen P. Titanium in medicine. Berlin: Springer; 2001. p. 25-53.

42. Richards RG, Perren SM. Implants and materials in fracture fixation. In: Ruedi TP, Buckley RE, Moran CG, editors. AO principles of fracture management. 2nd ed., New York: Thieme; 2007. p. 33-45.

43. Misenhimer GR, Peek RD, Wiltz LL, Rothman SL, Widell Jr EH. Anatomic analysis of pedicle cortical and cancellous diameter as related to screw size. Spine 1989; 14:367-72.

44. Sjo" stro"m L, Jacobsson O, Karlstro"m G, Pech $\mathrm{P}$, Rauschning W. CT analysis of pedicles and screw tracts after implant removal in thoracolumbar fractures. J Spinal Disord 1993; 6:225-31.

45. Esses SI, Botsford DJ, Kostuik JP. Evaluation of surgical treatment for burst fractures. Spine 1990; 15:667-73.

46. Shuman WP, Rogers JV, Sickler ME. Thoracolumbar burst fractures: CT dimensions of the spinal canal relative to postsurgical improvement. Am J Roentgenol 1985; 145:33741.

47. Aono H, et al. Surgical outcomes of temporary short-segment instrumentation without augmentation for thoracolumbar burst fractures. Injury (2016), http://dx.doi.org/10.1016/ j.injury.2016.03.003

48. McLain RF (2006) The biomechanics of long versus short fixation for thoracolumbar spine fractures. Spine 15 31(11 Suppl): S70-S79

Citation: Bhattrai B, Shah S. Efficacy of Short and Monosegment Spinal Fixations in Traumatic Incomplete Thoracolumbar Burst Fractures. JCMS Nepal. 2019; 15(3):197-201. 